\title{
Discriminação Planejada \\ A Seletividade do Currículo Oficial Paulista \\ Para os Anos Iniciais do Ensino Fundamental
}

\author{
Marlene Oliveira de Brito ${ }^{1}$ \\ Vitor Machado ${ }^{2}$
}

\begin{abstract}
Resumo
0 artigo apresenta resultados de pesquisa realizada com base no tratamento da diversidade étnico-racial e cultural no ensino. Apresentamos neste texto a análise do material didático disponibilizado pela Secretaria Estadual de Educação de São Paulo aos professores dos anos iniciais do Ensino Fundamental das escolas públicas estaduais. A partir das expectativas de aprendizagem do Guia de Planejamento e Orientações ao Professor, e com base na análise de conteúdo proposta por Bardin (1979), buscamos avaliar o tratamento que as agências estaduais oferecem à temática, sob a ótica da organização da sociedade e suas relações contraditórias entre capital e trabalho, raça e gênero, presentes nas políticas educacionais e nas práticas curriculares no cotidiano das escolas.
\end{abstract}

Palavras-chave: Discriminação planejada. Diversidade étnico-racial e ensino. Tradição seletiva.

\section{PLANNED DISCRIMINATION: THE SELECTIVITY OF THE OFFICIAL PAULISTA CURRICULUM FOR THE INITIAL YEARS OF FUNDAMENTAL EDUCATION}

\begin{abstract}
The article presents research results based on the treatment of ethnic-racial and cultural diversity in education. We present in this text, the analysis of the didactic material made available by the State Secretariat of Education of São Paulo to the teachers of the initial years of elementary school in the state public schools. Based on the analysis of content proposed by Bardin (1979), we seek to evaluate the treatment that the state agencies offer to the
\end{abstract}

1 Graduação em Pedagogia. Mestranda do Programa de Pós-Graduação em Docência para a Educação Básica - Universidade Estadual Paulista "Júlio de Mesquita Filho"(Unesp). azeviche2@ gmail.com

2 Departamento de Educação - Universidade Estadual Paulista "Júlio de Mesquita Filho" (Unesp). Pós-Graduação em Docência para a Educação Básica - Sociologia da Educação. v.machado@unesp.br 
theme, from the point of view of the organization of society and its contradictory relations Between capital and labor, race and gender, present in educational policies and curricular practices in the daily life of schools.

Keywords: Planned discrimination. Ethnic-racial diversity and education. Selective tradition.

Recebido em: 14/3/2017

Avaliações requeridas em: 28/3/2017

Aceito em: 22/11/2017 
Entre os desafios que compõem a prática docente na Educação Básica, o maior deles é acolher a diversidade. Essa dificuldade tem raízes na forma como a sociedade se organiza, nas relações contraditórias mantidas entre capital e trabalho, raça e gênero, com reflexos nas práticas curriculares do cotidiano das escolas.

As interações nos processos educacionais, com dimensões mais amplas da organização da sociedade capitalista, nem sempre são discutidas no ambiente escolar. Há muitos questionamentos no interior da escola, no entanto ainda permanecemos avaliando nossos métodos e ignorando a poderosa mensagem social que a escola veicula, a partir dos conteúdos que não problematiza, e "a importância da educação como condição prévia para qualquer atividade política" (APPLE, 2001, p. 35).

A questão central, que envolve uma parcela considerável de docentes, técnicos e teóricos da educação, é como desenvolver o conteúdo escolar de modo que ele seja absorvido mais rápida e eficazmente pelo conjunto dos estudantes. Essa centralidade dos métodos nas práticas pedagógicas mantém estreita ligação com o esvaziamento da dimensão política nos processos educacionais.

Assim, pautados na análise de conteúdo proposta por Bardin (1979) e pelas considerações de Apple (2001) acerca da função do currículo escolar na sociedade capitalista, avaliamos os documentos fornecidos pela Secretaria da Educação do Estado de São Paulo (Seesp), que servem como guia de planejamento e orientação ao professor, e compõem o currículo oficial das escolas públicas do Estado de São Paulo, especialmente o das séries iniciais do Ensino Fundamental. Procuramos evidenciar, a partir das Expectativas de Aprendizagem estabelecidas nos materiais, como são abordados os temas relacionados às questões étnico-racial e cultural.

É necessário destacar que, com o intuito de uniformizar o trabalho realizado em 5 mil escolas estaduais, a Seesp oferece uma base comum de conhecimentos e competências, desde 2008, por meio da Coordenadoria de Gestão da Educação Básica, com um currículo-base para os anos iniciais e anos finais do Ensino Fundamental e Ensino Médio. Denominamos, portanto, currículo oficial paulista os documentos oficiais e um conjunto de materiais dirigidos aos 
professores e aos estudantes: os Cadernos do Professor e do Aluno, organizados por disciplina, de acordo com a série, ano e bimestre. Neles são apresentadas Situações de Aprendizagem para orientar o trabalho do professor no ensino dos conteúdos disciplinares específicos e a aprendizagem dos alunos.

Com o resultado das nossas análises foi possível detectar a existência de uma engenharia de controle curricular exercida pelo poder estatal, que ignora a diversidade cultural existente em nossa sociedade, além de nos possibilitar compreender como esse controle curricular tem ampliado, nos anos iniciais, o que denominamos de discriminação planejada, estruturada e mantida pela tradição seletiva ${ }^{3}$ do currículo oficial.

\section{O Condicionamento da Prática Docente no Papel Estratégico da Educação Escolar}

Especialmente na última década, no contexto da educação pública estadual paulista, assistimos passivamente à retirada do controle de parte considerável do currículo e da didática das mãos dos professores. A criação de programas com produção e distribuição de materiais didáticos que compõem o currículo oficial do Estado de São Paulo, estrategicamente aliada a uma política de bonificação, tem nas avaliações de amplo espectro do Sistema de Avaliação de Rendimento Escolar do Estado de São Paulo (Saresp) ${ }^{4}$ e nas avaliações diagnósticas, por meio

\footnotetext{
3 Entende-se por "tradição seletiva", a partir das considerações de Apple (2001) retomando Williams (1978) e referindo-se ao movimento operário nos Estados Unidos, a ausência nos materiais curriculares mais utilizados da herança histórica de um determinado segmento significativo da população. No contexto desta pesquisa a expressão é tomada em apropriação ao se referir à ausência das histórias e culturas dos povos negros africanos, afro-brasileiros e indígenas no currículo oficial do Estado de São Paulo.

4 O Sistema de Avaliação de Rendimento Escolar do Estado de São Paulo (Saresp) é aplicado pela Secretaria da Educação do Estado de São Paulo e, de acordo com a pasta, tem como finalidade produzir um diagnóstico da situação da escolaridade básica paulista. No Saresp, os estudantes do $3^{\circ}, 5^{\circ}, 7^{\circ}$ e $9^{\circ}$ anos do Ensino Fundamental e da $3^{\mathrm{a}}$ série do Ensino Médio têm seus conhecimentos avaliados por meio de exame anual.
} 
do programa de Avaliação da Aprendizagem em Processo (AAP), ${ }_{5}^{5}$ meios eficazes de condicionamento e redução da prática docente a uma corrida por domínio de habilidades mensuráveis, alcance de metas e índices. Observamos uma dinâmica de controle real do "que se ensina", de "quem ensina" e "para quem se ensina".

No contexto paulista, uma "engenharia de controle" tem situado a atuação dos professores em uma complexa rede de conflitos: cumprir as determinações impostas pelo Estado ou questionar os sentidos da sua prática. Não é possível compreender essa dinâmica sem estabelecermos relações e identificarmos as materializações desse processo nas práticas educacionais.

Analisando as sociedades capitalistas, Apple (2001) demonstra que Estado e escola estão completamente articulados na produção de mercadorias culturais exigidas pela sociedade. Desta forma, aquilo que a escola produz - a mercadoria do conhecimento - apesar de não ser algo material, torna-se um produto economicamente vital. É nessa perspectiva que a escola se integra à conjuntura produtiva.

É evidente que o

Estado e "gestores educativos" para racionalizar e estandardizar o processo e o produto de ensino, para prescrever objetivos e conteúdos curriculares muito específicos, para definir todo o ensino como uma coleção mensurável de "competências", etc., encontram-se relacionados com uma longa história de tentativas de controle das professoras, em particular, e das trabalhadoras, em geral (APPLE, 2001, p. 35).

Assim, dadas essas condições, os laços que unem Estado e capital estão ancorados no controle da "economia", pelo conhecimento útil, materialmente produtivo e também no controle da "cultura", pela seletividade do que ensinar e dos valores a legitimar. Therborn (1980 apud APPLE, 2001), defende que a relação entre o Estado e os aparelhos de Estado, pode, frequentemente, ser entendida na base de relações de dominação de classe, à medida que o Estado interfere de modo

\footnotetext{
5 A Avaliação da Aprendizagem em Processo (AAP) é um exame criado pela Secretaria Estadual de Educação de São Paulo para medir o nível de desempenho dos estudantes ao longo do ano. Com caderno de questões e respostas o exame indica as habilidades que devem ser avaliadas de acordo com os níveis de proficiência estabelecidos para a série/ano.
} 
decisivo no funcionamento das escolas. Nesse contexto, o aparelho educativo tem o papel de "[...] garantir um fluxo de conhecimento técnico e de pessoal tecnicamente especializado e semiqualificado [...]" (THERBORN, 1980 apud APPLE, 2001), retirando essa obrigação das empresas, uma vez que todo esse processo concretiza-se por intermédio das políticas e prioridades curriculares e avaliativas.

O autor ainda alerta que é no cotidiano das pessoas que as ações consensuais, plenas de significados e ideologias, moldam a produção da vida. No plano educacional, esses consensos inserem-se nas práticas curriculares, nas formas que os conteúdos assumem e nas concepções de avaliação. É nesta perspectiva que as escolas, segundo Apple (2001, p. 90), além de ajudarem a selecionar e certificar a força de trabalho, também “[...] ensinam normas, valores, ensinamentos de uma determinada cultura, que contribuem para a hegemonia ideológica dos grupos dominantes".

No contexto escolar brasileiro, o controle curricular estruturado na seletividade dos conteúdos programáticos é herdeiro de processos históricos gestados no padrão de poder que emergiu do colonialismo. Essa herança não oferece espaço à diversidade cultural e social nas práticas curriculares, uma vez que não reconhece formas de produção de conhecimento que não sejam estabelecidas pelos padrões eurocêntricos. $\mathrm{O}$ fato de toda a base do saber veiculado nas escolas, das variadas áreas de conhecimento, ter como origem o continente europeu, não nos causa estranheza. Isso é posto e aceito como um padrão de normalidade. A faceta mais cruel dessa dinâmica foi a redefinição dos padrões culturais a um único paradigma, tendo como pano de fundo a dissolução dos conhecimentos produzidos por outros povos e grupos sociais diversos, além da descontextualização dos saberes da cultura popular e suas formas de transmissão.

Os estudos decoloniais, ${ }^{6}$ que se desenvolveram a partir das reflexões do Grupo Modernidade/Colonialidade, formado por intelectuais da América Latina, propõem a construção de um projeto epistemológico, ético e político

${ }^{6}$ Como ficaram conhecidas as reflexões do Grupo Modernidade/Colonialidade, formado por intelectuais da América Latina, que propõe a construção de um projeto epistemológico, ético e político a partir da crítica à modernidade ocidental eurocêntrica, em seus postulados históricos, sociológicos e filosóficos. 
baseado na crítica à modernidade ocidental eurocêntrica, em seus postulados históricos, sociológicos e filosóficos. Alguns representantes desses estudos, como Dussel (1995; 2002; 2005), Quijano (1994; 1998; 2002; 2010), Mignolo (1995; 2005), Grosfoguel (2003; 2011), Walsh (2005; 2009), Maldonado-Torres (2008; 2012) e Escobar (2009), têm revelado que as relações que se estabeleceram entre colonizadores e colonizados foram muito além das imposições políticas, econômicas e administrativas, uma vez que se mantiveram após a emancipação jurídico-política das colônias - séculos 19 e 20 - e adquiriram permanência com o padrão de poder que emergiu do colonialismo: a colonialidade.

Assim,

[...]apesar do colonialismo preceder a colonialidade, a colonialidade sobrevive ao colonialismo. Ela se mantém viva em textos didáticos, nos critérios para o bom trabalho acadêmico, na cultura, no sentido comum, na autoimagem dos povos, nas aspirações dos sujeitos e em muitos outros aspectos de nossa experiência moderna. Neste sentido, respiramos a colonialidade na modernidade cotidianamente (MALDONADO-TORRES, 2007, p. 131).

Esse paradigma que estabeleceu hierarquias entre saberes, conhecimentos e culturas, mantém-se intacto nesse processo que resulta de uma história de dominação e exploração. Segundo Oliveira e Candau (2010), de acordo com os autores do grupo Modernidade/Colonialidade ${ }^{7}$ as estruturas subjetivas, o imaginário e a colonização epistemológica ainda estão fortemente presentes. "Graças à colonialidade, a Europa pode produzir as ciências humanas como modelo único, universal e objetivo na produção de conhecimentos, além de deserdar todas as epistemologias da periferia do ocidente" (OLIVEIRA; CANDAU, 2010, p. 4). Além disso, podemos considerar ainda que a "colonialidade é um dos elementos

7 Grupo de pesquisa formado, em sua maioria, por intelectuais da América Latina que propõe a construção de um projeto epistemológico, ético e político a partir da crítica à modernidade ocidental eurocêntrica, em seus postulados históricos, sociológicos e filosóficos. A colonialidade do poder, do saber e do ser são conceitos centrais dentro do projeto de investigação. Seus principais expoentes são: o filósofo argentino Enrique Dussel, o sociólogo peruano Aníbal Quijano, o semiólogo e teórico cultural argentino-norte-americano Walter Mignolo, o sociólogo porto-riquenho Ramón Grosfoguel, a linguista norte-americana radicada no Equador Catherine Walsh, o filósofo portoriquenho Nelson Maldonado Torres, o antropólogo colombiano Arturo Escobar. 
constitutivos e específicos do padrão mundial do poder capitalista. Se funda na imposição de uma classificação racial/étnica da população mundial como pedra angular deste padrão de poder" (QUIJANO, 2005, p. 93).

Nessa perspectiva, todo um complexo de legado cultural e histórico é diluído em um conjunto de formas e padrões dominantes de valores. Nesses termos, a colonialidade impõe formas de produção de conhecimento, de geração dos saberes e criação do imaginário, atuando, inclusive, na construção da subjetividade dos indivíduos e na autoimagem que eles têm de si e de sua cultura. A dissolução dos conhecimentos, das cosmovisões, das realizações intelectuais, materiais e simbólicas, produzidas pela diversidade de povos e práticas sociais, é parte da mentalidade de longa duração que inferioriza grupos humanos com vistas à manutenção de uma organização social hierarquizada.

Os estudos do grupo Modernidade/Colonialidade têm produzido reflexões teóricas interdisciplinares que pretendem desconstruir a naturalização da epistemologia ocidental. Propõe formas de reconhecer outros conhecimentos com um olhar sobre as subjetividades excluídas. É nessas condições que Walsh (2009) debruça-se sobre os processos educacionais a partir de uma abordagem decolonial, a qual, entre outras questões, representa a luta a favor da visibilidade, do entendimento das diversas formas de conhecer, de ser, das lutas, da resistência, das práticas sociais, políticas e culturais dos povos subalternizados, contra o silenciamento, contra a não existência.

Na educação brasileira, podemos afirmar que o reconhecimento público das diferenças passou a receber contornos institucionais a partir da Constituição Federal de 1988, com o conjunto de dispositivos legais que dão início a uma política educacional voltada à afirmação da diversidade cultural e à educação das relações étnico-raciais nas escolas, a saber: a Constituição da República Federativa do Brasil de 1988, imputando como dever de Estado a obrigatoriedade do ensino a todos, condições de acesso e permanência e a pluralidade de ideias; a Lei n ${ }^{\circ}$ 10.639/03 (BRASIL, 2003), que altera o artigo 26A da Lei de Diretrizes e Bases da Educação Nacional (LDB) (BRASIL, 1996) e estabelece a obrigatoriedade do ensino da História e Cultura Afro-Brasileiras e Africanas nas escolas públicas e privadas dos Ensinos Fundamental e Médio; o Parecer 
do CNE/CP 03/2004 (BRASIL, 2004b), que aprovou as Diretrizes Curriculares Nacionais para Educação das Relações Étnico-Raciais e para o Ensino de História e Cultura Afro-Brasileiras e Africanas; a Resolução CNE/CP 01/2004 (BRASIL, 2004a), que detalha os direitos e as obrigações dos entes federados na instituição da Lei; a Lei 11.645/08 (BRASIL, 2008), que altera o artigo 26A da Lei de Diretrizes e Bases da Educação Nacional (LDB) (BRASIL, 1996) e estabelece a inclusão da obrigatoriedade do ensino da História e Culturas Indígenas; o Plano Nacional das Diretrizes Curriculares Nacionais para a Educação das Relações Étnico-Raciais e para o Ensino de História e Cultura Afro-Brasileira e Africana (BRASIL, 2009), em 2009; e a Lei no 12.796/13 (BRASIL, 2013), alçando a diversidade étnico-racial como princípio de ensino.

Os dispositivos legais sinalizam uma nova dimensão de interpretação e valorização das identidades culturais e realizações de povos historicamente marginalizados. Além disso, formam o arcabouço jurídico que, entre outras medidas, colocam "sob suspeita” o conteúdo programático do currículo praticado nas escolas básicas e superiores.

\section{A Engenharia de Controle da Prática Docente}

Pensando justamente em refletir sobre o significado da ausência de determinados conteúdos escolares na Educação Básica, é que empreendemos uma atenta e especial análise ao currículo escolar oficial do Estado de São Paulo direcionado aos anos iniciais do Ensino Fundamental. A intenção é identificar como esse currículo opera e quais significados estão presentes no material curricular oferecido pela Secretaria Estadual de Educação de São Paulo.

De acordo com as informações disponíveis pela Secretária da Educação do governo do Estado de São Paulo, o denominado "Currículo do Estado de São Paulo" (SÃO PAULO, 2016a), constitui-se como orientação básica para o trabalho do professor em sala de aula. As justificativas são apontadas nos seguintes termos: 
Para apoiar o trabalho realizado nas cinco mil escolas estaduais, a Secretaria da Educação do Estado de São Paulo desenvolveu, em 2008, por meio da Coordenadoria de Gestão da Educação Básica, um currículo base para os anos iniciais e anos finais do Ensino Fundamental e Ensino Médio. Com a medida, a Educação pretende fornecer uma base comum de conhecimentos e competências que [...] permita que essas unidades funcionem, de fato, como uma rede articulada e pautada pelos mesmos objetivos [...] (SÃO PAULO, 2016a).

Especificamente, nos anos iniciais do Ensino Fundamental, o Currículo Oficial do Estado de São Paulo apresenta dois programas como base curricular comum de formação dos alunos nessa etapa de ensino. Um deles é o "Programa Ler e Escrever" (SÃO PAULO, 2008), desenvolvido pelo conjunto de ações voltadas aos estudantes do $1^{\circ}$ ao $5^{\circ}$ ano do Ensino Fundamental, incluindo formação, acompanhamento, elaboração e distribuição de materiais pedagógicos. O outro é o Programa de Educação Matemática nos Anos Iniciais (Emai) (SÃO PAULO, 2012a), que tem como seu principal objetivo “[...] articular o processo de desenvolvimento curricular em Matemática, a formação de professores, a avaliação de desempenho dos estudantes e elementos chave de promoção da qualidade da educação."

O "Programa Ler e Escrever" (SÃO PAULO, 2008) passou a ser adotado nos anos iniciais do Ensino Fundamental das escolas públicas paulista no ano de 2008, instituído no ano anterior pela Resolução SE no 86/2007 (SÃO PAULO, 2016c). Inicialmente, tal Programa estava voltado somente ao aprendizado da Língua Portuguesa, quando em 2012, por meio da Resolução SE no 46/2012 (SÃO PAULO, 2012b), o governo do Estado de São Paulo, decidiu incluir um Inciso (Inciso III) ao Art. $1^{\circ}$ da Resolução SE 86/2007 (SÃO PAULO, 2016c), disciplinando também sobre o ensino da Matemática. Essas medidas adotadas pelo governo do Estado de São Paulo, significaram a instituição das Diretrizes Curriculares em Língua Portuguesa e Matemática, que passaram a ser seguidas pelas escolas de todo o Estado.

Mais tarde, no ano de 2015, a Secretaria Estadual de Educação ampliou sua atuação sobre o currículo das séries iniciais do Ensino Fundamental, criando para a área de História, Geografia e Ciências o Projeto "Memórias, Caminhos 
e Descobertas" (SÃO PAULO, 2015), voltado aos estudantes e professores. O material tem o intuito de ajustar a ação pedagógica, com propostas de atividades a serem realizadas em conjunto com os alunos, reunindo as disciplinas de História, Geografia e Ciências (SÃO PAULO, 2015).

Sobre a instauração desses programas até aqui citados, precisamos considerar dois pontos importantes. Um deles diz respeito ao conteúdo desse material - tema sobre o qual trataremos mais adiante - e o outro refere-se ao modus operandi da Secretaria de Educação do Estado de São Paulo, quanto à estruturação da matriz curricular, a fim de priorizar o ensino dos conteúdos das disciplinas de Língua Portuguesa e Matemática nos anos iniciais do Ensino Fundamental. Sobre esse assunto, devemos lembrar que, no Estado de São Paulo, a Resolução SE Nº 81/2011 (SÃO PAULO, 2016b), retirou a obrigatoriedade do ensino das disciplinas de História, Geografia e Ciências do $1^{\circ}$ ao $3^{\circ}$ ano do Ensino Fundamental. Por meio dessa Resolução, essas disciplinas passaram a fazer parte da matriz curricular somente no $4^{\circ}$ e $5^{\circ}$ ano, não podendo as avaliações externas, como a Avaliação da Aprendizagem em Processo (AAP) e o Saresp incidirem sobre elas.

É importante considerarmos ainda que o "Programa Ler e Escrever" (SÃO PAULO, 2008) vai além de uma intervenção pontual, uma vez que passa a determinar os rumos da educação pública paulista para os anos iniciais, com uma gama de profissionais, programas de formação, sistemas de avaliação e monitoramento, no intuito de garantir sua execução. Além disso, há de se destacar também que a Secretaria Estadual de Educação direciona a atuação dos professores por meio de um material didático-pedagógico por ela fornecido - "Guia de Planejamento e Orientações ao Professor - Sociedade e natureza” (SÃO PAULO, 2015), que apresenta um conjunto de sequências didáticas, ${ }^{8}$ a serem elaboradas a partir das Expectativas de Aprendizagem definidas para cada ano/série. De acordo com Bräkling (2013) em documento elaborado pela Coordenadoria de Gestão da Educação Básica (CGEB), órgão pertencente à Secretaria de Educa-

${ }^{8}$ Os cadernos de atividades são organizados por metodologia específica com base em situações de aprendizagem em que os conteúdos são apresentados em passos que contemplam de algum modo: o conhecimento prévio; a contextualização; realização da atividade de aprendizagem; acompanhamento; análise e avaliação da atividade; a síntese e, por vezes, a aplicação e experimentação. 
ção do Estado de São Paulo, tais expectativas de aprendizagem orientam todo o processo de ensino com clareza, objetividade e progressão coerente, diante das concepções de ensino assumidas e as suas implicações didáticas.

As expectativas definem as intenções básicas de aprendizagem de um determinado processo de ensino para um determinado período de tempo. Dito de outro modo, as expectativas definem a proficiência mínima que se pretende que seja constituída pelo aluno ao final de um processo de ensino específico, o qual pode ser determinado por diferentes períodos de tempo (mês, semestre, ano, segmento de ensino, por exemplo). [...]. As expectativas definem, portanto, a proficiência básica - e fundamental - que se pretende que o aluno construa no período determinado, e não o máximo possível a ser conseguido. Em contrapartida, ao definirem o que se espera que o aluno aprenda, as expectativas determinam necessidades de ensino (BRÄKLING, 2013, p. 5).

O fato é que as expectativas de aprendizagem tornam-se mensuráveis e formam a base para a elaboração dos exames externos diagnósticos, como a Avaliação da Aprendizagem em Processo (AAP) - realizada ao final de cada bimestre - e para as questões do Saresp, aplicado ao final de cada ano letivo. Os resultados do Saresp compõem o Índice de Desenvolvimento da Educação do Estado de São Paulo (Idesp): um indicador de qualidade que, na prática, atribui uma "nota" para cada escola da rede pública. A cada ano a Secretaria da Educação estabelece uma meta a cumprir para cada escola com base na "nota" do Idesp do ano anterior. O Idesp, por sua vez, é atrelado a uma política de bonificação, de modo que recebem um bônus anual na remuneração os professores e demais funcionários das escolas públicas estaduais que atingirem ou ultrapassarem a meta estabelecida. No que essa política interfere na sala de aula? Em todo o processo de ensino e planejamento do professor.

A Secretaria da Educação do Estado de São Paulo oferece material com aulas prontas, com base nas Expectativas de Aprendizagem determinadas para cada área e ano/série. Tais expectativas são avaliadas no decorrer do ano, por meio dos exames diagnósticos. Assim, os professores sabem, ao longo do ano, quais expectativas ainda estão defasadas, garantindo-lhes tempo de preparar os estudantes para o Saresp. O desempenho de cada escola no Saresp é um dos critérios para o acréscimo anual na baixa remuneração do professor. Com essa dinâmica, o governo estadual paulista estabelece um controle quase que irrestrito sobre as práticas curriculares das escolas públicas estaduais. 
Em nosso entendimento, são duas as consequências diretas e imediatas dessa engenharia que opera em franca expansão. Uma delas diz respeito à alienação do trabalho docente caracterizado pela escolha dos conteúdos, pelo estabelecimento dos objetivos, pelo planejamento da aula e pela avaliação da sua atuação e a dos estudantes. Todo esse processo é retirado do ofício do professor, uma vez que outras agências, que representam os interesses do Estado, são responsáveis por selecionar, planejar, avaliar e, inclusive, treinar o professor para apenas executar o planejamento alheio. A segunda implicação desse processo é a omissão desse currículo.

\section{A Discriminação Planejada no Currículo Oficial Paulista para os Anos Iniciais}

A forma articulada do currículo oficial paulista, que determina o conteúdo, o planejamento das aulas e os critérios de avalição, vem acompanhada de omissões em que o que não é dito é tão importante quanto o que esse currículo diz e dita na forma de conteúdos, permeados por interesses e exclusão de histórias inteiras de grupos étnicos e práticas socioculturais. Conforme alerta Apple (2001, p. 118), “[...] a ideologia se apresenta na forma de eloqüentes silêncios [...]", daí a necessidade de se investigar em um produto cultural não só o que ele excede em significados, mas também o que ele tende a excluir.

Assim, no seio da rotina das escolas, algumas das influências ideológicas que formam o tecido social ocorrem no âmbito da prática, em contextos reais de produção e reprodução de certas mercadorias culturais. São nestes contextos que "[...] a cultura da escola e o conhecimento formal expressos no currículo não respondem à história ou à experiência negra [...]”' (APPLE, 2001, p. 182), por exemplo.

$\mathrm{Na}$ tentativa de examinarmos como essa questão se apresenta no currículo oficial paulista, desenvolvemos uma análise a partir das expectativas de aprendizagem que constam nas "Orientações Curriculares do Estado de São Paulo - Anos Iniciais" (SÃO PAULO, 2013) e no "Guia de Planejamento e Orientações ao Professor - Sociedade e Natureza" (SÃO PAULO, 2015). Neste estudo adotamos como referencial teórico-metodológico a análise do 
conteúdo categorial proposta por Bardin (1979), agrupando as Expectativas de Aprendizagem em categorias, a fim de identificarmos se as orientações dadas aos professores possibilitam, a partir do currículo oficial praticado nas escolas estaduais paulista, o desenvolvimento de temas relacionados à diversidade étnico-racial e cultural.

No Quadro 2 apresentamos uma síntese das expectativas de aprendizagem do material denominado "Orientações Curriculares do Estado de São Paulo - Anos Iniciais” (SÃO PAULO, 2013). Como tal documento apresenta as Expectativas de Aprendizagem e Orientações Gerais para cada ano/série dos anos iniciais do Ensino Fundamental, separadamente, para as áreas de História, Geografia e Ciências, consideramos, para efeito deste estudo, apenas as que dizem respeito ao ensino de História. A partir do eixo "Sociedade e Natureza", estabelecemos três categorias de análise, por meio das quais foi possível observamos a ocorrência ou não das expectativas de aprendizagem de cada categoria. As categorias foram definidas conforme demonstrado no Quadro 1, a seguir:

$$
\text { Quadro } 1 \text { - Definição das categorias de análise }
$$

\begin{tabular}{llll}
\hline Categoria 1 & $\begin{array}{l}\text { Expectativas de aprendizagem } \\
\text { relacionadas ao conhecimento técnico e }\end{array}$ & $\begin{array}{l}\text { os aspectos pisam a explorar apenas } \\
\text { procedimental }\end{array}$ & conhecimento
\end{tabular}

Categoria 2 Expectativas de aprendizagem Ações que visam a estabelecer relações relacionadas às transformações sociais entre os fenômenos sociais em contextos espaçotemporais
Categoria 3 Expectativas de aprendizagem Ações que explorem, ou ao menos relacionadas à diversidade étnico-racial façam menção, à diversidade étnico- e cultural racial e cultural.

\section{Fonte: Os autores.}

Olhar para o currículo oficial paulista a partir das Expectativas de Aprendizagem mostrou-se importante, uma vez que, por meio delas determina-se a seleção de conteúdos, o encaminhamento das atividades e os critérios de avaliação. No contexto em questão, o domínio das Expectativas de Aprendizagem configura o objetivo final a ser atingido pelo estudante. 
A seguir, no Quadro 2, apresentamos de forma sistematizada a ocorrência das Expectativas de Aprendizagem em cada uma das categorias descritas no Quadro 1, com um exemplo de Expectativa de Aprendizagem de cada categoria, que consta nas Orientações Curriculares do Estado de São Paulo - anos iniciais (SÃO PAULO, 2013), a serem seguidas pelos professores no transcorrer do processo de ensino/aprendizagem.

Vejamos o que o Quadro 2 apresenta:

Quadro 2 - Expectativas de Aprendizagem presentes nas Orientações Curriculares do Currículo Oficial paulista para o ensino de História nos anos iniciais do Ensino Fundamental

\begin{tabular}{|c|c|c|c|c|c|c|}
\hline \multicolumn{7}{|c|}{ Eixo } \\
\hline \multicolumn{7}{|c|}{ Sociedade e Natureza } \\
\hline \multicolumn{2}{|r|}{ Categorias } & \multicolumn{5}{|c|}{ Número de Ocorrências } \\
\hline & & $1^{\circ}$ Ano & $2^{\circ}$ Ano & $3^{\circ}$ Ano & $4^{\circ}$ Ano & $5^{\circ}$ Ano \\
\hline 1 & $\begin{array}{l}\text { Expectativas de } \\
\text { aprendizagem } \\
\text { relacionadas ao } \\
\text { conhecimento } \\
\text { técnico e } \\
\text { procedimental }\end{array}$ & $\begin{array}{c}4 \\
\text { (Utilizar, } \\
\text { progressivamente, } \\
\text { vocabulário } \\
\text { relativo ao } \\
\text { conceito de tempo } \\
\text { na construção de } \\
\text { relatos históricos) }\end{array}$ & 3 & 3 & 3 & 4 \\
\hline & & $1^{\circ}$ Ano & $2^{\circ}$ Ano & $3^{\circ}$ Ano & $4^{\circ}$ Ano & $5^{\circ}$ Ano \\
\hline 2 & $\begin{array}{l}\text { Expectativas de } \\
\text { aprendizagem } \\
\text { relacionadas às } \\
\text { transformações } \\
\text { sociais em } \\
\text { contextos } \\
\text { espaçotemporais }\end{array}$ & 1 & 2 & 3 & 3 & $\begin{array}{c}3 \\
\text { (Compreender } \\
\text { a periodização } \\
\text { de tempo } \\
\text { histórico e suas } \\
\text { relações com a } \\
\text { transformação } \\
\text { da sociedade } \\
\text { brasileira. }\end{array}$ \\
\hline & & $1^{\circ}$ Ano & $2^{\circ}$ Ano & $3^{\circ}$ Ano & $4^{\circ}$ Ano & $5^{\circ}$ Ano \\
\hline 3 & $\begin{array}{l}\text { Expectativas de } \\
\text { aprendizagem } \\
\text { relacionadas } \\
\text { à diversidade } \\
\text { étnico-racial e } \\
\text { cultural }\end{array}$ & 0 & $\begin{array}{c}1 \\
\text { (Conhecer e } \\
\text { diferenciar } \\
\text { os diversos } \\
\text { instrumentos } \\
\text { de contagem de } \\
\text { tempo usados } \\
\text { por diferentes } \\
\text { sociedades ao } \\
\text { longo da história) }\end{array}$ & 0 & 0 & 0 \\
\hline
\end{tabular}

Fonte: São Paulo (2013). 
Ao analisarmos atentamente o Quadro 2, verificamos que ele possibilita uma visão panorâmica das expectativas de aprendizagem estabelecidas para o ensino de História em todos os anos/séries do segmento anos iniciais. Observamos no Quadro 2: na categoria 1 são 17 (dezessete) expectativas de aprendizagem para o ensino de História, em todo o segmento anos iniciais. Na categoria 2 encontramos 12 (doze) expectativas de aprendizagem. Em contrapartida, na categoria 3, em que se buscou observar a ocorrência de expectativas que tratassem direta ou indiretamente a diversidade étnico-racial e cultural, encontramos somente 1 (uma) expectativa de aprendizagem, indicada para o $2^{\circ}$ ano/série do segmento anos iniciais. Apenas uma única ocorrência foi encontrada, referente a essa categoria para os cinco anos/séries iniciais do Ensino Fundamental. Cabe ressaltar que ao desenvolver a análise, consideramos a expectativa de aprendizagem, mesmo que ela tenha apenas tangenciado a temática da diversidade étnico-racial e cultural, uma vez que no material observado não há ocorrência de expectativa de aprendizagem que aborde a temática de forma direta.

Podemos concluir que o currículo oficial paulista aplicado nas escolas públicas do Estado de São Paulo, para o ensino de História nos anos iniciais, não contempla em suas Expectativas de Aprendizagem a diversidade étnico-racial e cultural. Ao proceder desse modo, descumpre a Lei de Diretrizes e Bases da Educação Nacional (LDB) (BRASIL, 1996) em seu artigo 26 e a Lei 10.639/2003 (BRASIL, 2003), desconsiderando todo um conjunto de dispositivos legais que primam por uma política educacional voltada para a afirmação da diversidade cultural e a educação das relações étnico-raciais nas escolas.

Observamos ainda que no Estado de São Paulo o currículo oficial privilegia, em suas Expectativas de Aprendizagem no ensino de História nos anos iniciais do Ensino Fundamental, os aspectos procedimentais do conhecimento. Isso sugere a existência de um projeto de educação que pretende formatar um corpo de estudantes de acordo com padrões de organização, obediência e execução de tarefas, tal qual adverte Apple (2001). Um currículo que ignora a diversidade étnico-racial e cultural e ainda apresenta uma ênfase em aspectos procedimentais, passa uma poderosa mensagem social para os estudantes que atende. Não podemos ignorar o fato de que o arranjo curricular reflete-se nos 
encaminhamentos diários que, certamente, compromete o processo de formação integral dos estudantes que não se veem reconhecidos nos conteúdos programáticos do currículo.

$\mathrm{Na}$ análise do currículo oficial paulista a omissão sistemática de temas relacionados à questão étnico-racial cultural pode ser mais bem observada quando avaliamos, a partir das Expectativas de Aprendizagem, o material didático que orienta diretamente a prática docente, denominado Guia de Planejamento e Orientações ao Professor - Sociedade e Natureza (SÃO PAULO, 2015), conforme demonstramos no Quadro 3, a seguir:

Quadro 3 - Expectativas de Aprendizagem do Guia de Planejamento e orientações ao professor - História, Geografia e Ciências - Anos Iniciais

\begin{tabular}{|c|c|c|c|c|c|c|}
\hline \multicolumn{7}{|c|}{ Eixo } \\
\hline \multicolumn{7}{|c|}{ Sociedade e Natureza } \\
\hline \multicolumn{2}{|r|}{ Categorias } & \multicolumn{4}{|c|}{ Número de Ocorrências } & \multirow[b]{2}{*}{$5^{\circ}$ Ano } \\
\hline \multirow[b]{2}{*}{1} & \multirow{2}{*}{$\begin{array}{l}\text { Expectativas de } \\
\text { aprendizagem } \\
\text { relacionadas ao } \\
\text { conhecimento } \\
\text { técnico-científico }\end{array}$} & $1^{\circ}$ Ano & $2^{\circ}$ Ano & $3^{\circ}$ Ano & $4^{\circ}$ Ano & \\
\hline & & 14 & 25 & 23 & 25 & 33 \\
\hline \multirow[b]{2}{*}{2} & \multirow{2}{*}{$\begin{array}{l}\text { Expectativas de } \\
\text { aprendizagem } \\
\text { relacionadas às } \\
\text { transformações } \\
\text { sociais em } \\
\text { contextos espaço- } \\
\text { temporais. } \\
\end{array}$} & $1^{\circ}$ Ano & $2^{\circ}$ Ano & $3^{\circ}$ Ano & $4^{\circ}$ Ano & $5^{\circ}$ Ano \\
\hline & & 3 & 7 & 11 & 20 & 9 \\
\hline \multirow[b]{2}{*}{3} & & $1^{\circ}$ Ano & $2^{\circ}$ Ano & $3^{\circ}$ Ano & $4^{\circ}$ Ano & $5^{\circ}$ Ano \\
\hline & $\begin{array}{l}\text { Expectativas de } \\
\text { aprendizagem } \\
\text { relacionadas } \\
\text { à diversidade } \\
\text { étnico-racial e } \\
\text { cultural }\end{array}$ & $\begin{array}{c}2 \\
\text { (Reconhecer } \\
\text { diferentes } \\
\text { modos de vida } \\
\text { e estabelecer } \\
\text { relações com } \\
\text { o seu jeito de } \\
\text { viver com o de } \\
\text { outros povos; } \\
\text { Respeitar os } \\
\text { vários padrões } \\
\text { de cultura dos } \\
\text { povos) }\end{array}$ & $\begin{array}{c}1 \\
\text { (Conhecer e } \\
\text { diferenciar } \\
\text { os diversos } \\
\text { instrumentos } \\
\text { de contagem } \\
\text { de tempo } \\
\text { usados por } \\
\text { diferentes } \\
\text { sociedades } \\
\text { ao longo da } \\
\text { História) }\end{array}$ & 0 & $\begin{array}{c}1 \\
\text { (Comparar } \\
\text { diferentes } \\
\text { modos de } \\
\text { alimentação } \\
\text { entre os seres } \\
\text { humanos e } \\
\text { relacioná-los } \\
\text { às condições } \\
\text { sociais e } \\
\text { econômicas, } \\
\text { ambientais e } \\
\text { a pluralidade } \\
\text { cultural) }\end{array}$ & 0 \\
\hline
\end{tabular}

Fonte: São Paulo (2015). 
De acordo com o Quadro 3, o material analisado reúne as disciplinas de História, Geografia e Ciências e trata das orientações diretas à prática docente, contendo sequências didáticas e atividades que devem ser aplicadas, tendo como base as Expectativas de Aprendizagem para cada ano/série. Para efeito de análise, também consideramos o eixo Sociedade e Natureza e duas das categorias analisadas no Quadro 1 (Categoria 2 e Categoria 3), por observarmos a manutenção de um mesmo padrão, em boa parte das Expectativas de Aprendizagens apresentadas nas Orientações Curriculares para o ensino de História. Nas demais Expectativas de Aprendizagem desse material constatamos um padrão que se relaciona com a dimensão que consideramos ser parte de um conhecimento técnico e científico. Desse modo, a Categoria 1 passou a ser por nós denominada no Quadro 3 como Expectativas de Aprendizagem Relacionadas ao Conhecimento Técnico-Científico. Nessa categoria buscamos destacar as Expectativas de Aprendizagem que tratam apenas dos aspectos relativos ao conhecimento das Ciências Naturais apresentadas no material.

Assim, no Quadro 3, evidenciamos, a partir da análise das Expectativas de Aprendizagem, que tipo de conteúdo é privilegiado no material, no sentido de orientar a prática do professor na direção de temas relacionados às questões étnico-racial e cultural. Observamos, desse modo, que o material que reúne as disciplinas de Ciências, História e Geografia - teoricamente sugerindo um trabalho interdisciplinar - amplia o padrão observado no Quadro 2, que tratou, especificamente, das Orientações Curriculares gerais para o ensino de História. Se no Quadro 2 identificamos uma ênfase nas Expectativas de Aprendizagem relacionadas ao domínio de aspectos procedimentais do conhecimento, no material representado pelo Quadro 3 tal ênfase é substituída por um tratamento quase que exclusivo às Expectativas de Aprendizagem relacionadas à área das Ciências Naturais.

Nessas condições, temos o seguinte panorama no material direcionado aos estudantes e professores: na Categoria 1 encontramos 120 (cento e vinte) Expectativas de Aprendizagem em todos os anos do segmento; na Categoria 2 estão presentes 50 (cinquenta) Expectativas de Aprendizagem; na categoria 3 encontramos 4 (quatro) Expectativas de Aprendizagem: duas indicadas para o 
$1^{\circ}$ ano, uma para $2^{\circ}$ ano e uma para o $4^{\circ}$ ano. E do mesmo modo que observamos nas Orientações Curriculares para o ensino de História, as referências à diversidade étnico-racial e cultural são indiretas e generalistas.

Dessa maneira, os professores dos anos iniciais da educação pública estadual paulista têm em mãos um material que reúne três disciplinas - Ciências, Geografia e História - que trata de modo bastante desproporcional as Expectativas de Aprendizagem propostas no documento nas áreas destacadas. Como podemos verificar o Guia de Planejamento e Orientações ao Professor - História, Geografia e Ciências - Anos Iniciais, dedica à disciplina de Ciências Naturais 69,4\% das Expectativas de Aprendizagem a serem atingidas. Os restantes 30,6\% das Expectativas de Aprendizagem presentes no material em análise são "divididos" entre as disciplinas de História e Geografia. E desse total, apenas $1,7 \%$ das Expectativas de Aprendizagem apresentam referência indireta à diversidade étnico-racial e cultural.

Analisando os Quadros 2 e 3 constatamos que a Expectativa de Aprendizagem encontrada para o $1^{\circ}$ ano, em relação à referência feita à diversidade étnico-racial e cultural, é indireta e generalista, na medida em que não se preocupa em discutir de forma aprofundada os processos históricos e sociais que determinam os modos de opressão da população negra. Uma educação de qualidade só será possível se contribuir para que os estudantes compreendam o funcionamento das estruturas sociais opressoras. Somente assim criarão condições de atuar contrariamente a elas, criando espaços de resistência que poderão garantir o êxito do processo de transformação social contra a opressão racial.

Nossa análise revelou também que em relação ao $2^{\circ}$ ano, tanto o material analisado no Quadro 2 quanto no Quadro 3 apresentam a mesma Expectativa de Aprendizagem, mantendo o padrão indireto de abordagem da diversidade étnico-racial e cultural: "Conhecer e diferenciar os diversos instrumentos de contagem de tempo usados por diferentes sociedades ao longo da história" (SÃO PAULO, 2015, p. 14). Esse mesmo padrão pode ser constatado também quando analisamos o Quadro 3 e verificamos a única ocorrência observada na Expectativa de Aprendizagem apresentada para o $4^{\circ}$ ano: "Comparar diferentes modos de alimentação entre os seres humanos e relacioná-los às condições sociais e eco- 
nômicas, ambientais e a pluralidade cultural" (SÃO PAULO, 2015, p. 19). Esse padrão curricular "generalista" revela que o currículo do Estado de São Paulo tem tratado o tema da diversidade étnico-racial e cultural de maneira superficial. Santomé (1995) define como trivial os estudos realizados pelo currículo de forma superficial, na medida em que tais estudos passam a estar preocupados somente com os aspectos ligados ao costume alimentar, folclore, forma de vestir, rituais festivos e a decoração de suas habitações. Tudo isso contribui significativamente para silenciar as culturas das minorias sociais negadas na escola, pois

as situações sociais silenciadas até o momento e que normalmente se colocam como situações problemáticas na sociedade concreta na qual se encontra a escola (as etnias oprimidas, as culturas nacionais silenciadas, as discriminações de gênero, de idade, etc...) passam a ser contempladas, mas a partir de perspectivas de distanciamento, como algo que não tem a ver conosco, algo estranho, exótico, ou até mesmo problemático, mas, nesse último caso, deixando claro que sua solução não depende de nada em concreto, que está fora de nosso alcance (SANTOMÉ, 1995, p. 173).

Dessa forma, devemos compreender que a escola precisa refletir criticamente sobre o legado cultural da sociedade, rompendo com uma prática curricular comum que privilegia a memorização e o acesso a informações com base em estereótipos, ocultando as concepções de mundo que servem aos processos de opressão existentes em nossa sociedade.

Retomamos aqui a importante indagação de Apple (2001): "Quem mais [se] beneficia em última instância das formas através das quais as escolas e as práticas curriculares e de ensino no seu seio se encontram organizadas?” (p. 29).

Como pudemos demonstrar as Expectativas de Aprendizagem evidenciadas nos Quadros 2 e 3 representam dois materiais que compõem parte do currículo oficial do Estado de São Paulo para os anos iniciais: o Quadro 2 representa o material que oferece as diretrizes curriculares para o ensino de História nos anos iniciais, portanto, direcionado aos docentes; o Quadro 3 apresenta as Expectativas de Aprendizagem do material que contém sequências didáticas com atividades a serem desenvolvidas, portanto direcionado aos estudantes. São materiais com orientações distintas e específicas, estruturados a partir de expectativas de apren- 
dizagem para o segmento. Conforme observado, no entanto, além de privilegiar tipos específicos de conhecimento, ambos os negligenciam e descumprem a LDBEN (BRASIL, 1996) em seu artigo 26A, por parte das agências estaduais paulistas que direcionam o planejamento e a prática docente. O artigo 26A, como citado anteriormente, que institui a Lei 10.639/03 (BRASIL, 2003), estabelece a obrigatoriedade do ensino da História e Cultura Afro-Brasileiras e Africanas nas escolas públicas e privadas dos Ensinos Fundamental e Médio.

Sabemos que no ofício docente o planejamento tem um caráter essencial, estruturador e central. É o diferencial da sua profissionalidade, entendida como processo de formação que se dá também na atuação do professor, na intencionalidade que imprime em sua prática e na função social que assume, refletindo sobre os fenômenos que ocorrem no ambiente escolar e fora dele. De acordo com Apple (2001), o que vem ocorrendo na escola é uma intensa penetração de ideologias e práticas empresariais que se transferem para o interior da sala de aula na medida em que o professor não tem controle sobre o currículo e sobre sua ação pedagógica. Ao retirar do professor a possibilidade de realizar o que lhe é próprio do ofício para dar ênfase a um tipo de conhecimento, o Estado, em última instância, visa à manutenção das históricas relações que se estabelecem nos micro e macroespaços sociais. Segundo Apple (2001), agindo dessa forma a escola contribui significativamente para fortalecer a manutenção da dicotomia entre trabalho manual e trabalho intelectual, reforçando o processo de divisão social existente na sociedade capitalista. "O facto de a cultura, a linguagem e os valores dos grupos dominantes serem utilizados no ensino inicial em tais escolas leva a que as crianças pobres e das minorias étnicas sejam colocadas no lado manual da dicotomia" (APPLE, 2001, p. 101).

Como alerta o autor supracitado a aliança entre o Estado e o capital levou a escola a promover uma reestruturação conservadora em torno dos interesses ideológicos do capital, passando ela a assumir um papel estratégico nesse processo de divisão da sociedade em classes sociais, pois

[...] as escolas, como aparelhos de Estado, desempenham papéis importantes, apoiando a criação de condições necessárias, não só na acumulação de capital (ordenam, seleccionam e certificam um corpo de alunos hierarquicamente 
organizado), como na legitimação (mantêm uma ideologia meritocrática imprecisa, legitimando assim formas ideológicas necessárias para a recriação da desigualdade) (APPLE, 2001, p. 56).

A tese defendida pelo autor aponta para o fato de que as escolas funcionam também como um dos modos principais de produção de mercadorias culturais exigidas pela sociedade capitalista. Nas palavras de Apple (2001), o que a escola produz - a mercadoria do conhecimento - apesar de não ser algo material, torna-se um produto economicamente vital. É nesse contexto que se estruturam práticas curriculares com organização seletiva, privilegiando determinados conteúdos, além de excluir e silenciar referências históricas de parcela significativa dos estudantes que atende.

A constatação de Oliveira (2000 apud VERÍSSIMO, 2001, p. 11) evidencia a dimensão do que representa a negligência sistemática sobre a questão étnico-racial nas práticas curriculares das escolas:

\begin{abstract}
A questão racial se coloca de duas maneiras no interior da escola: a discriminação racial espontânea, que se dá de modo ocasional, isto é, decorre das atividades não-planejadas, da convivência natural escola/alunos, professor/ alunos, funcionários/alunos, alunos/alunos; e a que se dá pela não-inclusão do tema das relações raciais nas atividades intencionais, isto é, no planejamento escolar e de ensino.
\end{abstract}

No contexto da Educação Básica estadual paulista, entendemos que a discriminação também é intencionalmente planejada, produto do currículo oficial que ignora histórias, culturas, realizações e práticas socioculturais de parcela significativa dos estudantes que atende. Nessas condições, a prática docente precisa ser permeada por constantes questionamentos: A quem serve um currículo com essa configuração, a partir da engenharia de controle que as agências estaduais têm promovido no interior das escolas públicas paulistas? Que cidadãos são formados nessa conjuntura que não contempla as histórias e culturas da maioria dos estudantes que atende? Para essas indagações é que nosso estudo procura chamar a atenção, no intuito de contribuirmos com uma educação que supere as determinações impostas pela sociedade excludente. 
Desenvolver mecanismos de acesso dos estudantes às manifestações das práticas sociais e das culturas das quais ele é portador, além de compromisso profissional, deve ser o comprometimento ético de todo educador em um país plural. Especialmente, quando a discriminação racial apresenta-se como resultado de um projeto político educacional, sistematicamente planejado pelas agências estaduais, que impõe a professores e estudantes das escolas públicas estaduais paulistas o silenciamento. Conforme sinaliza Apple (2001), todavia, essa engenharia de controle possui contradições, e no seio delas são criados, por professores e estudantes, espaços de resistência.

No panorama que se apresenta, há urgência em se oferecer condições às escolas de potencializar as resistências e a capacidade de resposta às necessidades dos grupos excluídos dos espaços de formação e produção de conhecimento.

Há também uma enorme necessidade de ação curricular. Neste caso, não acrescentarei muito mais ao que já foi referido por outras pessoas que tiveram que lutar muito e arduamente para introduzir, nas escolas, material controverso, honesto, racial, sexual e economicamente progressista. [...] O reconhecimento daquilo que perdemos requer todavia não só uma análise teórica e histórica, mas também a produção ininterrupta de materiais curriculares e estratégias de ensino viáveis que possam ser usados nas salas de aula e em outros espaços (APPLE, 2001, p. 148).

Nesse contexto, chamamos a atenção para a importância dos processos de formação continuada, orientados no sentido de que o docente assuma o protagonismo de sua atuação em sala de aula e no sistema escolar. Tardif (2000), ao discutir a profissionalidade docente, sugere que o saber profissional, além de comportar um componente ético, é produzido por diferentes matizes e oriundo de diversas fontes: saberes das disciplinas, saberes curriculares, saberes da formação profissional e saberes da experiência. Sendo assim, faz parte da constituição da identidade docente e de sua profissionalidade resistir a sistemas que lhes retiram aquilo que é próprio de ofício: o planejamento das aulas, o estabelecimento de objetivos, a seleção de conteúdo, a adoção de metodologia, as estratégias de ensino e os critérios de avaliação, assim como a reflexão sobre os sentidos de sua atuação nos processos de formação no contexto escolar. 
Ainda segundo Tardif (2000, p. 17):

As práticas profissionais que envolvem emoções suscitam questionamentos e surpresa na pessoa, levando-a, muitas vezes de maneira involuntária, a questionar suas intenções, seus valores e suas maneiras de fazer. Esses questionamentos sobre a maneira de ensinar, de entrar em relação com os outros, sobre os efeitos de suas ações e sobre os valores nos quais elas se apoiam exigem do professor uma grande disponibilidade afetiva e uma capacidade de discernir suas reações interiores portadoras de certezas sobre os fundamentos de sua ação.

Assim, o compromisso ético do educador diz respeito ao modo como certas determinações e valores são questionados e compreendidos subjetivamente pelo indivíduo, orientando seu modo de agir, considerando os fins do ato de educar e suas relações com dimensões mais amplas da organização social. Nessa conjuntura, a atuação docente precisa ser contestadora, como um exercício de questionamentos, reflexão e ação constantes, a fim de que não se mantenha em uma posição confortavelmente resignada.

\section{Considerações Finais}

Ao longo do texto procuramos evidenciar como o processo educacional paulista seleciona, organiza e controla tipos específicos de conhecimento e como a exclusão materializa-se nas práticas curriculares no dia a dia da escola. As Diretrizes Curriculares Nacionais para a Educação das Relações Étnico-Raciais e para o Ensino de História e Cultura Afro-Brasileira e Africana (BRASIL, 2004a) são dimensões normativas, portanto reguladoras de caminhos que objetivam oferecer critérios e referências para o estabelecimento de ações que alterem as práticas curriculares, na direção de uma educação antirracista. O Plano Nacional de instituição das diretrizes étnico- raciais a ser posto em prática nas escolas apresenta as atribuições e exigências legais dos sistemas de ensino federais, estaduais e municipais. 
Como pudemos constatar, o currículo oficial paulista ignora os preceitos legais, no que se refere à temática étnico-racial e, ao fazê-lo, assume uma posição política, além de deixar à mercê da iniciativa dos docentes o desenvolvimento de ações nessa direção. Com o sofisticado sistema de controle, no entanto, tornam-se praticamente nulas as chances de ocorrerem alterações significativas nas práticas curriculares. Sem apoio nos processos de formação inicial e continuada, a atuação docente está sujeita à execução das tarefas planejadas com base na "tradição seletiva", que impõe à grande maioria dos estudantes que atende uma "não existência".

O desafio está em criar formas concretas de ação, com condições de fortalecer a resistência e superar a discriminação planejada do currículo oficial. Poucas coisas podem ser mais nobres do que o esforço de professores de resistir à "tradição seletiva" presente nos conteúdos do currículo oficial, que repõe a discriminação no âmbito do planejamento diário.

No contexto da educação pública estadual paulista, a discriminação não é apenas o produto dos conflitos que se estabelecem entre as demandas que envolvem as questões de classe, gênero e raça. Ela é sistematicamente planejada, produto da negação, das omissões e dos consensos que se estabelecem pelo silenciamento de histórias e práticas socioculturais de parcela considerável dos estudantes que atende.

\section{Referências}

APPLE, Michael Whitman. Educação e poder. Tradução João Menelau Paraskeva Porto: Porto Editora, 2001.

BARDIN, Laurence. Análise de conteúdo. Tradução Luís Antero Reta e Augusto Pinheiro. Lisboa: Edições 70, 1979.

BRÄKLING, Kátia Lomba. O que representam as expectativas de aprendizagem para a prática educativa? In: COORDENADORIA DE GESTÃO DA EDUCAÇÃO BÁSICA. Orientações didáticas fundamentais sobre as expectativas de aprendizagem de língua portuguesa. São Paulo: CGEB, 2013. Disponível em: <http://www.educacao.sp.gov.br/ a2sitebox/arquivos/documentos/963.pdf>. Acesso em: 21 maio 2016. 
BRASIL. CNE/CP. Resolução 01/2004. Institui Diretrizes Curriculares Nacionais para a Educação das Relações Étnico Raciais e para o Ensino de História e Cultura Afro-Brasileira e Africana. Diário Oficial da União, Brasília, 22 de junho de 2004a, Seção 1, p. 11.

. CNE/CP. Resolução 03/2004. Aprova as Diretrizes Curriculares Nacionais para Educação das Relações Étnico-Raciais e para o Ensino de História e Cultura Afro-Brasileiras e Africanas. Diário Oficial da União, Brasília, 19 de maio de 2004b.

. Lei 11.645/08. Altera a Lei no 9.394, de 20 de dezembro de 1996, modificada pela Lei no 10.639, de 9 de janeiro de 2003, que estabelece as diretrizes e bases da educação nacional, para incluir no currículo oficial da rede de ensino a obrigatoriedade da temática "História e Cultura Afro-Brasileira e Indígena". Diário Oficial da União, Brasília, 11 de março de 2008, p. 1.

. Lei n. 10.639. Altera a lei $n^{\circ} 9.394$, de 20 de dezembro de 1996, que estabelece as diretrizes e bases da educação nacional, para incluir no currículo oficial da rede de ensino a obrigatoriedade da temática "história e cultura afro-brasileira" e dá outras providências. Diário Oficial da União, Brasília, 10 de janeiro de 2003, p. 1.

. Lei $n^{\circ} 12.796$, de 4 de abril de 2013. Altera a Lei no 9.394, de 20 de dezembro de 1996, que estabelece as diretrizes e bases da educação nacional, para dispor sobre a formação dos profissionais da educação e dar outras providências. Diário Oficial da União, Brasília, p. 1, 5 de abr. 2013.

. Lei $\mathrm{n}^{\circ}$ 9.394, de 20 de dezembro de 1996. Estabelece as diretrizes e bases da educação nacional. Diário Oficial da União, Brasília, p. 27.833, 23 dez. 1996.

. Ministério da Educação. Grupo de Trabalho Interministerial. Contribuições para a Implementação da Lei 10.639/2003. Proposta de Plano Nacional de Implementação das Diretrizes Curriculares Nacionais da Educação das Relações Etnicorraciais e para o Ensino de História e Cultura Afro-Brasileira e Africana. 2009. Disponível em: <http:// portal.mec.gov.br/index.php?option=com_docman\&view=dow nload $\&$ alias $=1852$ -diretrizes-curricularespdf\&category_slug=novembro-2009-pdf\&Itemid=30192>. Acesso em: 21 out. 2016.

DUSSEL, Enrique. Ética da libertação: na idade da globalização e da exclusão. Petrópolis: Vozes, 2002.

. Europa, modernidade e eurocentrismo. In: LANDER, Edgardo (Org.). A colonialidade do saber: eurocentrismo e ciências sociais. Perspectivas latino-americanas. Buenos Aires, Argentina: Clacso, 2005. (Colección Sur Sur).

. Filosofia da libertação: crítica à ideologia da exclusão. São Paulo: Paulus, 1995. 
ESCOBAR, Arturo. Una minga para el postdesarrollo. América Latina en Movimiento. In: La Agonía de un Mito: Cómo Reformular el Desarrollo?, ano XXIII, p. 26-30, jun. 2009. Disponível em: <http://www.alainet.org/es/active/38111>. Acesso em: 16 jan. 2016.

GOSFOGUEL, Ramóm. La descolonización del conocimiento: diálogo crítico entre la visión descolonial de Frantz Fanon y la sociología descolonial de Boaventura de Sousa Santos. In: Formas-Otras: Saber, nombrar, narrar, hacer. Training Seminar de jóvenes investigadores en Dinámicas Interculturales, 4., 2011, Barcelona. Barcelona: Fundación Cidob, 2011. p. 97-108.

. Colonial Subjects. Puerto Ricans in a Global Perspective. Berkeley: University of California Press, 2003.

MALDONADO-TORRES, Nelson. A topologia do ser e a geopolítica do conhecimento. Modernidade, império e colonialidade. Revista Crítica de Ciências Sociais, n. 80, p. 71-114, mar. 2008.

La descolonización y el giro de (s) colonial. Chiapas, México: Universidad de la Tierra, 2012.

. Sobre la colonialidad del ser: contribuiciones al desarrollo de un concepto. In: CASTRO-GOMÉZ, S.; GROSFOGUEL, R. (Org.). El giro decolonial: reflexiones para una diversidad epistémica más allá del capitalismo global. Bogotá: Siglo del Hombre Editores; Universidad Central; Instituto de Estudios Sociales Contemporáneos y Pontificia Universidad Javeriana; Instituto Pensar, 2007.

MIGNOLO, Walter. A colonialidade de cabo a rabo: o hemisfério ocidental no horizonte conceitual da modernidade. In: LANDER, E. (Org.). A colonialidade do saber: eurocentrismo e Ciências Sociais - perspectivas latino-americanas. Buenos Aires: Clacso, 2005. (Colección Sur).

The Darker Side of the Renaissance. Ann Arbor: The University of Michigan Press, 1995.

OLIVEIRA, Iolanda de. Relações raciais e educação: recolocando o problema. In: MUNANGA, K. (Org.). O racismo no mundo contemporâneo. Cadernos Penesb. Relações Raciais - Discussões Contemporâneas, Niterói: Intertexto, n. 2, p. 105-121, 2000.

OLIVEIRA, Luiz Fernandes de; CANDAU, Vera Maria Ferrão. Pedagogia decolonial e educação antirracista e intercultural no Brasil. Educação em Revista, Belo Horizonte, v. 26, n. 1, p. 15-40, abr. 2010.

QUIJANO, Anibal. Colonialité du Pouvoir et Démocratie en Amerique Latine. Futuro antérieur: Amérique Latine, Democratie Et Exclusão. Paris: L'Harmattan, 1994.

. A colonialidade e modernidade racionalidade. In: MIGNOLO, Walter; ESCOBAR, Arturo. A globalização e a opção descolonial. Londres: Routledge, 2010. 
QUIJANO, Anibal. Colonialidade do poder, eurocentrismo e América Latina. In: A colonialidade do saber: eurocentrismo e ciências sociais. Perspectivas latino-americanas. Buenos Aires: Clacso; Consejo Latinoamericano de Ciencias Sociales, 2005.

Colonialidade, poder, globalização e democracia. Novos Rumos, ano 17, n. $37,2002$.

. Estado nación, ciudadanía y democracia: cuestiones abiertas. In: GONZÁLEZ, Helena; SCHMIDT, Heidulf (Org.). Democracia para una nueva sociedad. Caracas: Nueva Sociedad, 1998.

SÃO PAULO. Currículo do Estado de São Paulo. 2016a. Disponível em: <http://www. educacao.sp.gov.br/curriculo>. Acesso em: 21 maio 2016.

. FDE. Programa de Educação Matemática nos Anos Iniciais (EMAI). São Paulo, 2012a. Disponível em: <http://lereescrever.fde.sp.gov.br>. Acesso em: 15 jun. 2016. Acesso em: 21 maio 2016.

. FDE. Programa Ler e Escrever. São Paulo, 2008. Disponível em: <http://lereescrever.fde.sp.gov.br>. Acesso em: 15 jun. 2016. Acesso em: 21 maio 2016.

Secretaria da Educação. Guia de Planejamento e Orientações ao Professor $5^{o}$ ano. Volume 1. Versão Preliminar. Memórias, caminhos e descobertas - Sociedade e Natureza. São Paulo, 2015. Disponível em: <http://lereescrever.fde.sp.gov.br/Handler/ ExibImagem.ashx?isnsaj=656\&arq=S>. Acesso em: 21 maio 2016.

Secretaria da Educação. Orientações Curriculares do Estado de São Paulo -Ensino Fundamental/Anos Iniciais. 2013. Disponível em: <http://www.cdcc.usp.br/ cda/PARAMETROS-CURRICULARES/Sao-Paulo-Faz-Escola/Ciclo-I/orientacoes_estado_cie_his_geo.pdf>. Acesso em: 21 maio 2016.

. Secretaria da Educação. Resolução SE 46/12, de 25-4-2012. Dispõe sobre formação em serviço do Professor Educação Básica I e dá providências correlatas. São Paulo, 2012b. Disponível em: <http://www.educacao.sp.gov.br/lise/sislegis/detresol. asp?strAto=201204250046> . Acesso em: 21 maio 2016.

. Secretaria da Educação. Resolução SE 81/2011 de 16-12-2011. Estabelece diretrizes para a organização curricular do ensino fundamental e do ensino médio nas escolas estaduais. Disponível em: <http://siau.edunet.sp.gov.br/ItemLise/arquivos/81_11. HTM>. Acesso em: 21 maio 2016 b.

. Secretaria da Educação. Resolução SE no 86/2007 de 19-12-2007. Institui, para o ano de 2008, o Programa "Ler e Escrever", no Ciclo I das Escolas Estaduais de Ensino Fundamental das Diretorias de Ensino da Coordenadoria de Ensino da Região Metropolitana da Grande São Paulo. Disponível em: <http://siau.edunet.sp.gov.br/ItemLise/arquivos/86_07.HTM?Time=4/13/2013\%205:37:2>. Acesso em: 21 maio 2016c. 
SANTOMÉ, Jurjo Torres. As culturas negadas e silenciadas no currículo. In: SILVA, Tomaz Tadeu da (Org.). Alienígenas na sala de aula: uma introdução aos estudos culturais em educação. Rio de Janeiro: Vozes, 1995.

TARDIF, Maurice. Saberes profissionais dos professores e conhecimentos universitários: elementos para uma epistemologia da prática profissional dos professores e suas consequências em relação à formação para o magistério. In: Revista Brasileira de Educação, n. 13, jan./fev./mar./abr. 2000.

THERBORN, Goran. The ideology of power and the power of ideology. London: Verso, 1980.

VERÍSSIMO, Maria Valeria Barbosa. Política educacional e construção de identidade no espaço escolar: crianças negras. In: REUNIÃO DA ANPED, 27., GT Afro-brasileiros e Educação, n. 21, 2011. Disponível em: <http://27reuniao.anped.org.br/gt21/t215.pdf>. Acesso em: 15 maio 2016.

WALSH, Catherine. Interculturalidad, conocimientos y descolonialidad. Signo y Pensamiento. Bogotá, vol. 24, n. 46, p. 39-50, jan./jun. 2005.

Interculturalidad, Estado, Sociedad: Luchas (de)coloniales de nuestra época. Universidad Andina Simón Bolivar, Ediciones Abya-Yala, Quito, 2009. Disponível em: <http://www.flacsoandes.edu.ec/interculturalidad/wpcontent/uploads/2012/01/ Interculturalidad-estado-y-sociedad.pdf> . Acesso em: 20 maio 2016.

WILLIAMS, Raymond. Cultura e sociedade. São Paulo: Companhia Editora Nacional, 1978. 